\title{
Aula, autoria e reconhecimento: implicações para a pesquisa sobre os currículos da escola básica no Brasil*
}

\author{
Class, authorship and recognition: implications for research on \\ basic education curricula in Brazil
}

\section{Espacio áulico, autoría y reconocimiento: implicaciones para las investigaciones sobre el currículum de la educación básica en Brasil}

LUCIANO MENDES DE FARIA FILHO**

\begin{abstract}
RESUMO
Este artigo aborda as relações entre pesquisadores e escola básica, problematizando o reconhecimento da autoria, questão vinculada ao amplo tema da integridade na pesquisa científica. Para isso, introduzem-se, inicialmente, aspectos da pesquisa acadêmica em educação e da escola básica no Brasil, e se apresentam contribuições para pensar a aula em sua dimensão autoral, assim como as implicações disso para as pesquisas sobre currículos. Através deste trabalho, busca-se dar visibilidade às possibilidades de pensar a aula como texto, indicando potencialidades e limites dessa perspectiva. Finalmente, apontam-se alguns dos desafios que se apresentam para os pesquisadores do currículo e para os professores em geral a partir do trabalho com esse ponto de vista.
\end{abstract}

Palavras-chave: Autoria. Escola básica. Pesquisa em educação. Professores. Pesquisadores.

\begin{abstract}
This article questions the authorship recognition in the relations between researchers in education and basic education school, a subject linked to the theme of integrity in research. In order to do this, aspects of academic research in education and basic school in Brazil are initially introduced and contributions are presented to think about the class in its authorial dimension as well as the implications of this for curriculum research. Through this work we seek to give visibility to the possibilities of thinking the lesson as a text, indicating the potentialities and limits of these perspectives and highlighting some of the challenges they present for curriculum researchers and for teachers in general.
\end{abstract}

Keywords: Authorship. Basic school. Education research. Tachers. Researchers.

\section{RESUMEN}

Este artículo aborda las relaciones entre investigadores en educación y escuela básica focalizando en la problematización del reconocimiento de autoría, asunto vinculado al amplio tema de la integridad en la investigación científica. Para eso, inicialmente se introducen aspectos de la investigación académica en educación y de la educación básica en Brasil y se presentan contribuciones para pensar la dimensión autoral del aula y las implicaciones de esa perspectiva para las investigaciones sobre currículum. A través de este trabajo se pretende dar visibilidad a las posibilidades que emergen al pensar la clase como texto y se indican potencialidades y limites de esa perspectiva. Además, se presentan algunos desafíos que este punto de vista ofrece para los investigadores del currículo y para los profesores en general.

Palabras clave: Autoría. Educación básica. Investigación en educación. Maestros. Investigadores.

\footnotetext{
*Conferência proferida na mesa-redonda "A pesquisa em currículo, cultura e suas relações com a educação básica", ocorrida no IV SEMINÁRIO WEB CURRÍCULO e XII ENCONTRO DE PESQUISADORES EM CURRÍCULO, realizados na PUC-SP, no período de 21 a 23 de setembro de 2015.

**Professor Titular da Faculdade de Educação da UFMG, Coordenador do Projeto Pensar a Educação Pensar o Brasil - 1822/2022. E-mail: <lucianomff@ uol.com.br>.
} 


\section{A PESQUISA EM EDUCAÇÃo E A escola básica. Professores, AULA E AUTORIA}

Gostaria, pois, que a fala e a escuta que aqui se trançarão fossem semelhantes às idas e vindas de uma criança que brinca em torno da mãe, dela se afasta e depois volta, para trazer-lhe uma pedrinha, um fiozinho de lã, desenhando assim ao redor de um centro calmo toda uma área de jogo, no interior da qual a pedrinha ou a lã importam finalmente menos do que o dom cheio de zelo que deles se faz (BARTHES, s/d, p. 41).

Problematizar as relações que hoje se estabelecem entre os pesquisadores da área de educação e a escola básica implica recuperar (ou reafirmar) a noção de autoria como uma das importantes dimensões do reconhecimento dos colegas da escola básica. Nesse sentido, aborda-se neste trabalho a aula em sua dimensão autoral e algumas das implicações disso para as pesquisas sobre os currículos. Para tanto, retomam-se apontamentos sobre a relação entre a pesquisa que se realiza na universidade e a escola básica no Brasil para, em seguida, aproximar-se da temática da aula em sua dimensão autoral. Enfatizam-se as ricas possibilidades de se pensar a aula como texto e apontamse, em seguida, os limites dessa perspectiva. Depois, por meio de uma referência à dimensão performática da aula e para os repertórios postos em cena pelos professores (e alunos), indaga-se sobre as aproximações entre a aula e a obra de arte. Finaliza-se apontando alguns dos desafios que essas perspectivas colocam para os pesquisadores do currículo e para os professores em geral.

Quando se preparava este trabalho, foi feita a releitura do texto de Roland Barthes sobre a aula. Trata-se, como se sabe, de sua aula inaugural na cadeira de Semiologia Literária no Collège de France, pronunciada em 7 de janeiro de 1977. Na retomada do texto, captou-se o trecho apresentado como epígrafe acima. O que chamou a atenção foi, além da singeleza e sensibilidade que ali estão postas, o universo simbólico da situação descrita. Não por acaso, na continuidade do texto, Barthes afirma:

Quando a criança age assim, não faz mais do que desenrolar as idas e vindas de um desejo, que ela apresenta e representa sem fim. Creio sinceramente que, na origem de um ensino como este, é preciso aceitar que se coloque sempre um fantasma, o qual pode variar de ano a ano (BARTHES, s/d, p. 41).

Pesquisa, escola e aula são coisas que fascinam. Fala-se dessas coisas para exorcizar fantasmas e elaborar a experiência de ser e estar no mundo como professor. $\mathrm{O}$ que as crianças fazem brincando, os adultos tentam fazer, incessantemente, falando! O problema é que, lá e cá, nem sempre dá certo! Mas é uma aposta, acima de tudo, necessária! Que se aposte, pois!

\section{A PESQUISA EM EDUCAÇÃO E A ESCOLA BÁSICA ${ }^{1}$}

Nos últimos anos, em diversas situações, ao intervir no debate público sobre os sentidos da educação e, também, naquelas discussões que focam as relações entre a pesquisa e a pós-graduação em educação e a escola básica, tem-se sido enfático em afirmar que não se pode debitar na conta dos pesquisadores a suposta ou real baixa qualidade da escola pública brasileira. Seja nos fóruns de educação, seja naqueles que reúnem os agentes do sistema nacional de Ciência e Tecnologia (Conselho Nacional de Desenvolvimento Científico e Tecnológico - CNPq, Coordenação de Aperfeiçoamento de Pessoal de Nível Superior - Capes, fundações estaduais de amparo à pesquisa), tem-se afirmado que o conhecimento produzido e acumulado pela área não apenas é responsável por fundamentar e operacionalizar boa parte das políticas educacionais que deram certo nos últimos anos. Mas, se levado em conta pelas políticas educacionais, pode contribuir significativamente para a melhoria do conjunto da educação brasileira.

Pode-se dizer que muito se sabe, mas, infelizmente, as políticas pouco incorporam daquilo que foi e é produzido na área. Estas fazem, e de forma exagerada, um elogio à ignorância!

Mas, por outro lado, pode-se perguntar também: foram, são e serão boas todas as políticas e práticas baseadas nos conhecimentos e nos modos de conhecer? Não se tem dúvida do compromisso dos pesquisadores e alunos com a escola básica, com seu melhor funcionamento e com sua qualidade. E não se tem dúvida, também, de que há variáveis importantes que condicionam os modos de conhecer. Portanto, os conhecimentos interpõem barreiras importantes na sua utilização para dar suporte às práticas e políticas educacionais.

Uma delas é, por exemplo, a distância que separa os professores e pesquisadores universitários e suas condições de vida e trabalho daqueles que se dedicam à educação básica, sobretudo na rede pública. Tal distância, produzida historicamente, é continuamente atualizada, inclusive pelo investimento de muitos colegas, nas

\footnotetext{
Essa seção é, quase toda, repetição de parte da conferência realizada pelo(a) autor(a) na abertura do I Encontro de Pesquisa em Educação da Região Sudeste em São João Del Rei), em 12 de outubro de 2014, organizado pela Associação Nacional de Pesquisa e Pós-Graduação Regional Sudeste (Anped Sudeste). Aquilo que poderia ser a reafirmação de autoria é considerado, nos critérios atuais de metrificação da produção intelectual autoplágio. $\mathrm{O}(\mathrm{A})$ autor(a) evoca, em sua defesa, o fato de que, sendo diversas as situações de presença, como são as aulas e os eventos, o enunciado e a enunciação de um mesmo texto jamais serão a sua mera repetição.
} 
desigualdades quanto ao reconhecimento, ao salário, à formação, às condições de trabalho, dentre outros aspectos. Estes, muitas vezes, levam, inclusive, a enormes dificuldades de reconhecimento do destino comum: não por acaso, não são poucas as vezes em que há dificuldades de considerar os professores da educação básica como colegas.

Ora, o problema é que tal distância não é, e não pode ser, abolida pelo conhecimento. Daí, também, a falta de reconhecimento dos pares do conhecimento que se produz sobre eles, sobre suas práticas e escolas. Talvez, por isso, exista a reiteração do discurso acerca da distância entre a universidade e a escola básica.

Há outro aspecto que se quer salientar. Trata-se do distanciamento dos professores e pesquisadores universitários em relação à escola básica como um direito, ou, dito de outra forma, da recusa, hoje, em se ser usuário da escola básica. Como se sabe, um dos grandes problemas que se enfrentam contemporaneamente, no Brasil, em relação à qualidade da escola básica pública diz respeito ao fato de as camadas médias abrirem mão do direito à educação pública - como, de resto, foi feito com a saúde e com o transporte público. O que reflete na mentalidade segregadora que não suporta a convivência com o outro que chega com a expansão.

Tal circunstância, no que se refere ao aspecto específico que se quer aqui salientar, faz com que sempre que se fale em mudar a escola pública se está falando em reformar a escola dos filhos dos outros. Isso porque os nossos filhos e filhas estão frequentando as escolas privadas. Pergunta-se, a esse respeito, se seria possível ficar tão à vontade em aplicar nessas escolas aquilo que se defende, a partir dos conhecimentos e opiniões que se tem. Finalmente, chama-se a atenção para outra dimensão dos efeitos nem sempre desejáveis dos conhecimentos e das práticas acadêmicas sobre as políticas educacionais e atividades docentes. Se, de um lado, é preciso pensar que os professores, colegas da escola básica, são produtores de conhecimentos e sujeitos ativos na apropriação das discussões e conhecimentos propostos pelo mundo acadêmico; de outro, não se pode deixar de considerar o peso da universidade como lugar de enunciação.

Pergunta-se, por exemplo, se não se tem levado para a escola certas questões, certas discussões, certos conflitos que são ótimos para movimentar a pesquisa, mas que são também desestabilizadores e desorganizadores da escola, ou até mesmo desmotivadores, quando incorporados como política educacional.

Se essa suspeita é minimamente fundada, há aqui uma dimensão ética fundamental sobre a qual se deve debruçar mais. Evidentemente, não se trata de questionamento in totum da possibilidade de que os conhecimentos, produzidos a partir de modos peculiares de conhecer, possam contribuir para a elevação da qualidade da escola básica pública. Definitivamente não é isso! Trata-se, sim, de se questionar sobre os limites dos conhecimentos e, como diz o amigo Marcos Cezar Freitas, perguntar pelos grandes problemas trazidos, às vezes, pelas boas soluções propostas. Assim como raramente se aceita, por razões éticas inclusive, submeter filhos e filhas a experiências de formação que se consideram negativas para eles, mesmo que isso vá contra as convicções políticas que se tenha (e por isso, por exemplo, eles são colocados nas mais tradicionais instituições de ensino). Convida-se a pensar sobre a possibilidade de que conhecimentos e convicções já estabelecidos sobre a escola nem sempre são as melhores saídas para a escola pública.

\section{Professores, AULA E AUTORIA}

Apesar de se considerar - e aqui se fala de professores (ou pesquisadores) universitários (ou acadêmicos) - que a autoria, tal como esta foi produzida e reconhecida em diversos campos do conhecimento e/ou das práticas culturais nos dois últimos séculos, seja uma forma singular de reconhecimento, ainda hoje pouco se mobiliza para discutir (e reconhecer) a sua dimensão. Ao se fazer isso, está se negando também a discutir e a instituir práticas de autoria desses colegas, as quais são, sempre, como se sabe, exercícios de reconhecimento pessoal, social e, logo, de fortalecimento político. O que representa um desafio para a área, inclusive porque existem dificuldades até para discutir as práticas de coautoria que ocorrem entre colegas professores universitários ou entre alunos.

Mas a questão é mais complexa. Se a autoria é uma forma por excelência de reconhecimento, qual poderia ser o papel dos pesquisadores para incentivar e reconhecer as práticas de autoria autonomamente desenvolvidas pelos colegas da escola básica? Não estaria aqui uma estratégia importante de reconhecimento e empoderamento dos professores da escola básica? Não seria esta uma tática importante de reestabelecimento de uma relação de novo tipo com o conhecimento e com o conhecer por parte desses colegas? Não estaria aí, também, uma boa oportunidade para o reconhecimento da relatividade entre o conhecimento que se tem e os modos de conhecer universitários ou acadêmicos?

Bem se sabe que vários colegas e grupos pelo país afora têm se dedicado a realizar e a problematizar as pesquisas do tipo colaborativo realizadas entre professores universitários e aqueles da escola básica. Eles têm trazido contribuições significativas para a discussão dos modos de produção e apropriação (tanto no sentido emprestado a esse termo por Michel Foucault quanto por Michel de Certeau) dos conhecimentos na área. E, também, propõem o estabelecimento de uma relação mais horizontal entre os 
pesquisadores, entendidos estes não apenas como aqueles de perfil acadêmico, mas como o conjunto daqueles que participam das experiências de colaboração.

No entanto, mesmo com todos os avanços observados, é perceptível que a autoria, via de regra, é reconhecida aos pesquisadores acadêmicos. O desafio que se apresenta aqui é, inclusive, o do questionamento às culturas acadêmicas consagradas (muitas revistas, por exemplo, não aceitam publicar textos que não tenham como autor ou coautor uma pessoa com o título de doutor). Ou, o que parece mais produtivo, a ampliação e consagração dos canais de veiculação de conhecimentos e de experiências que estejam em diálogo como esses novos arranjos produtivos.

Outro desafio é inverter a ordem do movimento de colaboração: em praticamente todas as experiências de colaboração que se tem conhecimento, o movimento é da universidade para a escola básica, nunca o contrário. Ou seja, são os professores universitários, pesquisadores acadêmicos, que se dispõem a colaborar com os colegas da escola básica, sendo muito mais rara a experiência inversa em que os professores da universidade reconheçam a importância da colaboração dos professores da escola básica para estudarem, reverem e produzirem conhecimento sobre as práticas pedagógicas universitárias.

Nas pesquisas, colaborativas ou não, os pesquisadores, muitos deles professores(as) da escola básica inseridos nos programas de pós-graduação, indagam-se sobre as questões pedagógicas escolares. Nessas indagações, sobretudo nos últimos anos, a sala de aula e, o que não é o mesmo, a aula são "temas" que ganharam uma legitimidade epistemológica antes desconhecida. Numa rápida revisão da literatura sobre o tema aula, na pesquisa em educação, verifica-se que é um tema amplamente tratado na disciplina, sobretudo no campo da didática. Em enfoques que vão desde as "receitas" de boas aulas até a inutilidade ou a impossibilidade das mesmas, há uma rica e variada aproximação do tema, sobretudo pelos estudos que consideram a sala de aula como o "coração da escola". Também, aqui, o mais comum é focalizar as aulas dos outros, aquelas que ocorrem na escola básica, sendo mais escassos os trabalhos que problematizam sistematicamente a aula, também no ensino superior, como "espaço de conhecimento, lugar de cultura" (PENIN, 1994).

Poucos, no entanto, são os trabalhos que lidam com a dimensão autoral da aula. Entre estes, há alguns que tratam dessa dimensão ao considerar a aula como texto, enfoque no qual se sobressai a dimensão autoral e, portanto, de reconhecimento da prática pedagógica dos professores.

Essa visão é explorada de maneira muito peculiar e criativa por Ilmar Mattos, professor da Pontifícia
Universidade Católica do Rio de Janeiro (PUC-Rio), reconhecido pesquisador do campo da história e exprofessor da escola básica no Rio de Janeiro. Falando para seus colegas da história, ele ressalta que a aula é uma narrativa histórica tão legítima quanto aquelas dos textos, didáticos ou não, que servem de suporte ou de referência à prática dos professores. Mais do que isso, reagindo a uma pretensa superioridade do bacharelado, que forma o verdadeiro historiador, em relação à licenciatura, que forma o simples professor, mero repetidor do conhecimento já produzido, Ilmar Mattos propõe:

Uma leitura singular que revela o fato de os professores de história estarmos imprimindo à nossa prática cotidiana um significado diverso, provocando talvez uma surpresa e rejeitando uma inferioridade. De modo categórico, afirmamos ainda uma vez que, por meio de uma aula, também se conta uma história; que, ao se contar uma história por meio de aula, também se faz história; e que somente ao se fazer história por meio de uma aula nos tornamos professores de história. Por lermos de um modo singular uma proposição, podemos afirmar que também somos autores. Mas o fazemos não para afirmar uma semelhança, e sim para sublinhar a diferença que nos identifica (MATTOS, 2006, p. 11).

Apesar de sublinhar as diferenças, Ilmar Mattos não afirma que a aula como texto seja absolutamente distinta e separada das produções textuais e impressas produzidas pelos demais historiadores. Pelo contrário, como qualquer texto, a aula é um intertexto que "se constitui na condição necessária para revelar um novo autor - o professor de história" (Mattos, 2006, p. 12). Advoga ele:

A aula de história como texto é criação individual e coletiva a um só tempo; criação sempre em curso, que permanentemente renova um objeto de ensino em decorrência de novas leituras, de outras experiências vividas, da chegada de novos alunos, dos encontros acadêmicos e das conversas com os colegas de ofício, do surgimento de novos manuais didáticos, das decisões emanadas das instâncias educacionais e das questões, dos desafios e das expectativas geradas pelo movimento do mundo no qual vivemos, em sua dimensão local ou global. Mas o seu renovar permanente é sobretudo o resultado da prática cotidiana do ensino-aprendizagem de nossa disciplina; e porque o professor de história disto tem consciência é que se torna possível a aula como texto (MATTOS, 2006, p. 14).

A remissão ao texto de Ilmar Mattos permite estabelecer com bastante clareza não apenas a ideia da aula como um texto, mas o caráter coletivo dessa atividade por meio da qual o professor e o próprio aluno se constituem como autores. No âmbito do texto e, mais do que isso, na prática político-pedagógica e acadêmica do seu autor (!), 
essa proposição é defendida como uma forma de reconhecimento dos professores. E, não por acaso, é apresentada, provocativamente, como certa "desforra" contra os historiadores-escritores que se autorreconhecem como os únicos e verdadeiros historiadores!

Aula, texto, conhecimento, autoria seriam, assim, articulados num potente discurso de reconhecimento (e autoconhecimento) dos professores da escola básica. No entanto, há que se perguntar se não se está, ainda aqui, num regime em que o reconhecimento dos professores da escola básica se dá pela captura dos mesmos pela gramática e pela estratégia de reconhecimento que é própria do campo acadêmico científico moderno: a autoria de textos. Ou, dizendo de outro modo, seria possível falar da necessidade de reconhecimento da aula como trabalho autoral dos professores - de todos os professores, e não apenas da escola básica -, reconhecendo a sua dimensão textual e, ao mesmo tempo, liberando-a das amarras do texto?

A aula, se texto, seria mais literatura do que ciência, sem, no entanto, desta se desligar completamente. Mas não é este, em certo sentido, o lugar mesmo das ciências humanas? Concebendo a aula como obra autoral que se estabelece no entroncamento, no encontro entre a arte e a ciência, não estaria, na verdade, resgatando a proposta dos pais da pedagogia contemporânea que sempre assombraram os defensores de uma pedagogia científica que articula racionalmente meios e fins com o intuito de bem ensinar? A esse respeito, conviria mais uma vez lembrar Roland Barthes quando afirma, a propósito da história e da aula, que "a ciência pode, portanto, nascer do fantasma. É a um fantasma, dito ou não dito, que o professor deve voltar anualmente, no momento de decidir sobre o sentido de sua viagem; desse modo, ele se desvia do lugar em que o esperam, que é o lugar do Pai, sempre morto, como se sabe; pois só o filho tem fantasmas, só o filho está vivo" (BARTHES, s/d, p. 42).

Tal perspectiva compreende o professor não como alguém submetido às amarras do outro, das estratégias dos "poderosos" (gestores, políticos, pesquisadores, autores de livros etc.) e das táticas dos "sem poder" (alunos, pais etc.), e sim o constitui como um outro da enunciação, da autoria e da autoridade. Mais do que estar "submetido a" ou "submetendo a", ele está em "relação com", o que repõe a questão do poder no coração da educação ou, se preferirem, no coração da sala de aula!

Nesse sentido, cada aula que se encerra, que os professores encerram, é uma obra autoral complexa e acabada, apesar de incompleta. A sua articulação (ou encerramento!) num continuum - num currículo, por exemplo - é sempre uma aposta e, sobretudo, fruto de um trabalho narrativo elaborado a posteriori. Nessa perspectiva, a pesquisa sobre o currículo é uma indagação sobre a falta que, baldados os esforços dos professores e dos curriculistas os mais diversos, jamais poderá ser preenchida ou anulada.

No entanto, assim como o ensino, promessa nunca realizada, pois que o vital é o desejo de aprender e não o de ensinar, é uma responsabilidade da qual os professores não podem abrir mão, a indagação sobre os sentidos dos currículos é uma responsabilidade daqueles que se ocupam do acolhimento das novas gerações no mundo. Ou, como diria Hannah Arendt, "a essência da educação é a natalidade", e esta nos impõe inexoravelmente a responsabilidade de educar (ARENDT, 1997, p. 223ss).

Mesmo considerando, como assevera Paul Ricoeur, que essas narrativas sejam necessárias à história, à subjetividade e à identidade modernas, e que a hermenêutica moderna sobre estas se debruça, buscando interpretar os seus múltiplos sentidos, é possível e, pensase, necessário, articular a essa pedagogia dos sentidos uma outra, a pedagogia da presença, para lembrar os termos da filosofia proposta por Hans U. Gumbrecht (2012).

A aula, como situação de presença, como experiência, demanda a produção de estratégias de pesquisa e categorias de entendimento que a busquem entender como relação complexa e íntegra, apesar de sempre incompleta, entre sujeitos e destes com suas circunstâncias, entre elas, o conhecimento. Deslocar o olhar do pesquisador e do professor, interessados no currículo, do conhecimento para as circunstâncias, ainda é um dos desafios que se colocam para a prática docente e investigadora.

Deslocar o olhar do conhecimento pode significar, também, buscar captar, na densidade da aula, da sala de aula - ficando-se apenas nesse complexo universo que é a escola -, as performances e os repertórios mobilizados, atualizados e inventados pelos professores, alunos e demais agentes escolares para promover os variados currículos presentes no ambiente escolar ${ }^{2}$.

Performances e repertórios, como o conjunto dos recursos - intelectuais, sensitivos, de ação - disponíveis aos sujeitos numa determinada época ou situação, não por acaso, remetem ao universo das artes, repondo a possibilidade e a necessidade do reconhecimento da autoria e da irrepetibilidade da aula. Se cada aula é uma obra pronta, acabada, um dos principais desafios dos pesquisadores em currículo talvez esteja em constituir condições para que os professores - da educação infantil à

\footnotetext{
${ }^{2}$ Quando se fala em performance e repertórios, tem-se em vista a elaboração de Charles Tilly sobre esses termos, na medida em que o autor trata da história e da sociologia dos movimentos sociais (2008), apesar de reconhecer as dificuldades de sua apropriação para tratar do universo da sala de aula. No entanto, no campo da educação, o assunto é amplamente discutido. Ver, a esse respeito, v. 35, n. 2, da revista Educação e Realidade (2010), que traz vários artigos sobre o assunto.
} 
pós-graduação - reconheçam-se na obra, ou seja, na aula, e subvertam os cânones de reconhecimento de autoria e, por que não, de autorreconhecimento.

Por fim, sem dúvida, uma boa maneira de se fazer isso, é se reconhecer como professor e, desse modo, sendo autor das aulas na universidade. Essa pode ser uma chave para que se possa lançar sobre as próprias aulas na universidade, sobre a própria obra, e não apenas sobre as dos outros que atuam na escola básica, um olhar atento e responsável. O ensino superior e, mais particularmente, a universidade como espaço-tempo dos "impossíveis da educação" pode revelar muito daquilo que se desconhece sobre a escola básica, pois, como dizia Chico Buarque, o poeta: "Quem não a conhece não pode mais ver pra crer. Quem jamais a esquece não pode reconhecer".

\section{REFERÊNCIAS}

ARENDT, Hannah. Entre o presente e o passado. 4. ed. São Paulo: Perspectiva, 1997.

BARTHES, Roland. A aula. São Paulo: Cutrix, s/d.

GUMBRECHT, Hans U. Graciosidade e estagnação. Rio de Janeiro: Contraponto; Ed. PUC-Rio, 2012.

MATTOS, Ilmar R. Mas não somente assim! Leitores, autores, aulas como texto e o ensino-aprendizagem de história. Tempo, Rio de Janeiro, v. 11, n. 21, p. 5-16, jul./dez. 2006.

PENIN, Sonia T. de Sousa. A aula: espaço de conhecimento, lugar de cultura. Campinas: Papirus, 1994.

TILLY, Charles. Contentious performances. New York: Cambridge University Press, 2008.

Recebido em 01-04-2017

Aprovado em 20-06-2017. 